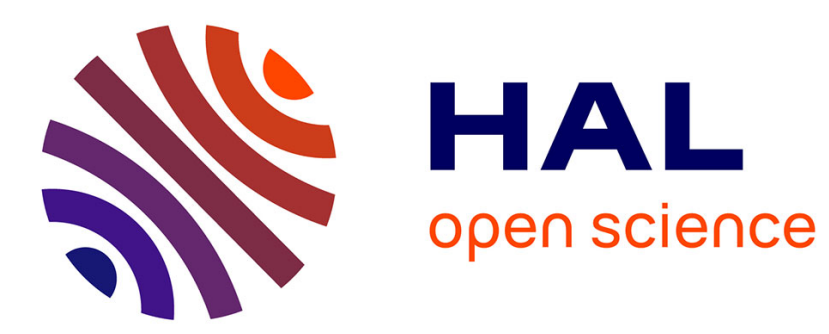

\title{
Teenagers learning languages out of school: what, why and how do they learn? How can school help them?
}

\author{
Sophie Bailly
}

\section{To cite this version:}

Sophie Bailly. Teenagers learning languages out of school: what, why and how do they learn? How can school help them?. P. Benson et H. Reinders (eds). Language Teaching and Learning Beyond the Classroom, Palgrave MacMillan, à préciser, 2011. hal-00520329

\section{HAL Id: hal-00520329 \\ https://hal.science/hal-00520329}

Submitted on 22 Oct 2010

HAL is a multi-disciplinary open access archive for the deposit and dissemination of scientific research documents, whether they are published or not. The documents may come from teaching and research institutions in France or abroad, or from public or private research centers.
L'archive ouverte pluridisciplinaire HAL, est destinée au dépôt et à la diffusion de documents scientifiques de niveau recherche, publiés ou non, émanant des établissements d'enseignement et de recherche français ou étrangers, des laboratoires publics ou privés. 


\section{Teenagers learning languages out of school: what, why and how do they learn? How can school help them?}

Bailly Sophie

ATILF/CRAPEL/UMR 7118 CNRS Nancy Université

Sophie.Bailly@univ-nancy2.fr

Key words: motivation; learning skills; independent learning; autonomy development; high school students.

\section{Introduction}

Due to the shortage of language teachers in France, some schools are no longer able to promote the development of multilingual and multicultural competences that society and individuals value. Meanwhile, the traditional extensive ${ }^{1}$ group language teaching model favoured in French schools is being challenged by increasing access to out-of-school means of learning foreign languages due for instance to the development of international exchanges and new communication media. The globalized world provides a variety of resources for satisfying language learning needs when school is not enough. Thanks to the Internet, resources for learning are easily accessible to almost anyone, including to school students, who can nowadays learn school subjects including foreign languages almost without going to class or being taught.

This chapter explores the relationships between in-school and out-of-school learning of foreign languages that are not taught at school. It draws on a research project that was designed to explore the conditions under which high school students can succeed in independent language learning (Bailly et al 2008). First of all, I will present the project on which this research is based. Then I will present findings about the students' out-of-school language learning under the following headings: the languages the students study outside school and why, the way they learn out of class, and the difficulties they meet.

\section{The context of the research}

The research was carried out over a period of four years in an urban high school in the East of France. This school is a lycée des métiers, meaning that all the students have chosen to specialise in a field related to the building industry, either in a vocational curriculum leading to a trades or professional qualification (such as plumbing, carpentry, or masonry) or in a technical curriculum preparing a higher education diploma (technical degree). The students are from 15 to 21 years old. Most of them are currently perceived by the education system as lacking the literacy and learning skills required for the study of general academic subjects such as French, English, History or Mathematics and have thus been directed towards technical or vocational studies.

The school promotes international exchanges and relationships (with institutions in Finland,

\footnotetext{
${ }^{1}$ Extensive learning, as opposed to intensive learning, refers to the way a given amount of time dedicated to learning is distributed in a long or short period of time. For instance, 25 hours could be done in one week (intensive learning) or in twenty-five weeks (extensive).
} 
Great-Britain, USA) but the study of foreign languages is not a key objective for the students. At this school the study of only one foreign language (German or English) is made compulsory, whereas the norm in French secondary education at high school level is to study two foreign languages. This means that students have to give up one of the two languages they were studying during the first four years of secondary education at the collège.

The English teachers had felt concerned about the contradiction between the international ambitions of the school and the rather restrictive foreign language education policy. A survey at the beginning of the year 2006 had shown that around ten percent of the students in the first and second year of high school (twenty students) would be interested in studying an optional second foreign language and had asked for languages that were not taught at school. These were either a language that they had studied at school before and had had to give up when arriving at the lycée (Spanish for example), or a family language (Wolof, Turkish, Arabic, Spanish or Portuguese), or a language they had started to learn outside of school or family contexts (for example Japanese). For these students, the only way to study this second language was by learning by themselves at home. During the research we found that some of them were already doing this with more or less success before the programme was launched.

So it was that the English teachers decided to promote and support the study of a second foreign language by offering a flexible learning scheme based on free choice and independent learning. Being experimental, the programme is restricted to volunteer students. It provides various facilities that students can choose to use or not:

- advisory sessions (Gremmo 1995, Reinders 2008) with a professional advisor to support and prepare independent learning;

- learning material on a website (http://www.languesenligne.blogspot.com/) specially designed for the project and accessible from anywhere;

- individual or group conversations with native speakers of the target language, organized at school.

The advisory session is a key feature of this system. Only the first meeting is compulsory and during this the advisor explains the programme and its principles and negotiates short-term objectives and methodology with the student. Then the student, still in negotiation with advisor, will decide whether or not to attend another advisory session. The following sessions are devoted to helping the learners identify their strengths and weaknesses in learning, and to helping them to learn more efficiently. The students, whether they elect to continue advisory sessions or not, are supposed to learn outside school, or at school, if they want to, but outside of curricular class time. They study at their own pace and choose their own methods and resources, including advisors and native speakers working for the school. They are neither corrected, nor assessed, nor graded by teachers if they do not want to be. If they decide to leave the program, their overall school results will not be affected.

The system is thus totally designed to enhance the process of becoming a self-directed learner. It is based on the will or the capacity of the students to take control of their learning. It enables students to see themselves in a different learning role, one where they are more active, responsible and autonomous since they work only for their own benefit.

A small group of ten very motivated learners joined the programme in 2007, the first year it was officially launched as an experimental project under the control of the local academic administration. In 2008, thirty students (out of two hundred) expressed interest in the scheme 
and fifteen actually joined the programme. In 2009 there were fifty interested students (a quarter of the target public) but only thirty could actually join the programme due to the organisational difficulties (number and availability of advisors, lack of space at the school for advisory sessions and tutoring) caused by this unexpected increase in demand. So far, the languages chosen by the students have been Spanish, Italian, Japanese, Russian, Dutch, French Sign Language, Turkish, Arabic, German, Portuguese, Wolof and Dari.

After three years of experimentation the programme is no longer an innovation at this school. It is well established in the English Department and the teachers would like to extend it to some of their groups of English students. The head of the high school is supportive of the project and she has agreed to build a physical self-access language centre that will enable more students to join the programme under better conditions. In December 2009 the programme received an award from the European Union (European Languages Label).

\section{The research}

The original overall aim of our project was less to explore out-of-class learning than to find school-based solutions for supporting students' independent learning and autonomy development. But as the programme was designed to support the learning of languages that are not taught in class, and as the school has at the moment no in-house self-access centre (SAC), it is by essence centred on out-of-class learning. It is quite natural, then, for students to inform advisors and researchers about what and how they learned outside class and on the difficulties and support they found outside school and at school.

The study presented here attempts to answer the following questions:

1) What languages do students learn outside school and why?

2) How do they learn out-of-class and with what results?

3) What difficulties do they meet in the process?

We used an ethnographic method: questionnaires, observations, and recordings of advisory sessions and of research interviews. Observations were centred on the learning materials that students brought to the advisory sessions, their spoken and written use of the target language observed during the interviews and the way they used the project website. The learners' discourse on their learning process outside school gave us access to their strategies (through their verbalisation of working practices ${ }^{2}$ ), and their perceptions of in-class and out-of-class learning (through their verbalisation of beliefs and attitudes). Our study deals with a relatively small number of students and is qualitative rather than quantitative. Thus, I will not be providing figures and tables of statistics but will present examples of various students'

\footnotetext{
${ }^{2}$ Taking into account the Goffmanian theory of face, our data might be biased in certain ways. Asked what they do to learn, without having been observed while learning, students may well have declared what they thought was expected from them in this situation. They might have wanted to make a good impression on the interviewer. But at the same time there is little reason to think that they deliberately lied to the researchers. They might have tried to idealize their involvement in their learning process. But the overall impression was that they seemed fairly honest, expressing both positive and negative aspects of their experience, and critical too, providing arguments to back their position. Even if they do not do all the things they claim to do, they certainly demonstrate the ability to describe, at least, what they would or could do if they were learning a foreign language out of school.
} 
working practices and attitudes that the data revealed.

\subsection{The languages students study outside school}

Since the beginning of the project we identified twelve different languages: Spanish, Italian, Japanese, Russian, Dutch, French Sign Language, Turkish, Arabic, German, Portuguese, Wolof and Dari. This diversity can be explained by differences in the students' personal "life trajectory" (Giddens 2003). The choice of language can relate to family history and context (Bronfenbrenner 1979) as well as to student's expectations, aspirations, plans and projects for the future. Our study highlights some ingredients of the motivational dynamics (Lantolf and Genung 2000) that are strongly linked to the learner's identity.

We identified three main reasons to study these languages. Firstly, some students chose to study a language with the clearly formulated academic goal of gaining additional points for the secondary education final exam that also allows entry to university (Baccalauréat) and to a technical degree. So they choose either a foreign language they have studied before, such as Italian, German or Spanish, or a country of origin language officially recognized by the French education system, such as Arabic or Turkish. Their interest is utilitarian or pragmatic. They have a clear idea of what they need to learn and of what they will gain in the process.

Secondly, other students choose a language for reasons that have more to do with identity and family history. Most are descendants of immigrants who want to communicate with grandparents or to keep in touch with a distant relative abroad. This is the case for languages such as Italian, Spanish, and Portuguese, as many immigrants from southern Europe came to work in the East of France up until the second part of the twentieth century. Here, motivation is related to the learner's history and social identity.

The third category includes students with motivations of a different type. The case of Japanese is rather interesting. Students' reasons for studying Japanese can be described as 'emotional' and are of two kinds. Most of them are fond of, if not crazy about, the Japanese culture in general (food, architecture) and Mangas in particular and envisage themselves travelling to or settling down in Japan in the future. The other Japanese learners are these Manga fans' friends or admirers. They chose to study this language because a person they want to be close to loves Japan. For this type of motivation the language-learning project has something to do with socializing and with feelings.

Amongst this category are found students for whom language is an expression of their love for something: love for a culture or language; and love for people close to this language and culture. For example, although this can only be an assumption as we have no data to confirm it, one of the students at school put so much enthusiasm and imagination into learning Turkish that it occurred to us that the friend she had been chatting with on the Internet was maybe more than just a friend. There was also one student who said he wanted to learn Dutch to make friends at rock festivals in the Netherlands. For these students, studying a foreign language is a means of connecting with others or of discovering the world. For others, process seems to be more important than linguistic product. For instance, one student chose Dari, a Persian language spoken in Afghanistan, explaining to his advisor that he wanted to write subtitles and credits for James Bond movies to put online. He did not learn much Dari during the year but established a positive relationship with his advisor.

Some students combine elements of the three types of motivation we identified. Some learn a family language for taking a degree (Italian, Spanish, Arabic), some combine love for the language with love for learning and some love their family language and culture. 
Thus motivations for the language seem to be oriented towards the past (family history) of each student, the present (socializing, flirting), or the near or distant future (end of studies diploma, working abroad). The mastering of a second foreign language represents one element students identify as necessary for reaching certain goals: getting a degree, travelling or working abroad, strengthening family bonds, making friends and building self-confidence.

\subsection{The way students learn out of class}

During advisory sessions and research interviews we systematically asked students to describe how they learned. We identified two sets of activities that students select and combine in order to learn.

Firstly, students apply a conventional set of learning techniques that have clearly been learned at school, such as the following 'serious' activities:

- doing grammar, vocabulary, pronunciation, comprehension and expression exercises;

- learning the alphabet;

- learning by heart;

- writing down grammar rules;

- using dictionaries;

- taking notes in a notebook;

- assessing language progress by reference to a grade or a mark;

- using school material from previous FL classes;

- translating unknown words;

- translating sentences.

Secondly, we discovered a set of "lighter" (Darasawang and Reinders 2010) or less conventional activities strongly connected to students' lives and environment, such as conversation, playing, or watching television, thus confirming other studies (Hyland 2004, Murray 2004, Palfreyman 2006, Benson and Chick in press). These activities favour receptive skills and are strongly connected with personal interests and hobbies from outside school. They include popular culture and entertainment material:

- watching Japanese animes or reading mangas

- using almost exclusively songs by their favourite singer;

- having conversations with a native speaker;

- chatting with a friend in the target language;

- watching an Anglo-American blockbuster movie or serial in another language;

- playing games on the Internet;

- watching football results on an Italian TV channel;

- going to the kebab restaurant to listen to conversations in Turkish;

- reading a book written in French about the target country;

- using a traveller's phrase-book

If we try to correlate students' choice of activities with their motivation, we find that serious activities seem to be more frequently found in seriously motivated learners (the Manga fans for instance, or the diploma seekers) whereas the lighter activities seem to cluster around less seriously motivated learners (the socialisers, the identity seekers). But this is still only a hypothesis at this stage of the research. 
Thus, the students learning repertoires are composed of items taken from the two sets of activities above. Of course, not all students do all of them. Some have very little idea of how to set about learning, but most of them can use several techniques. It happens that a student uses one technique or method for several weeks or months. For instance, one student discovered that she could learn by using only songs and applying a few techniques and tools. She listened to songs, translated the lyrics, transcribed them, imitated the singer and learned the songs by heart. She used video clips, a dictionary, lyrics transcriptions and, when available, translations in French. She kept on using this method as long as she remained satisfied with it. More research has to be done to understand what makes students choose a specific activity rather than another and to assess the efficiency of their strategic choices in terms of language acquisition, but we can make some guesses.

The 'serious activities' are clearly the result of conventional class learning skills that students transfer to out-of-class study of another language. For instance, students use their old school books or teacher's websites providing pre-structured activities. These serious activities (learning an alphabet, doing drills, learning by heart, translating, answering questions) are very similar to homework activities assigned by a teacher except that here students have control. They play the teacher's role by selecting for themselves what to learn and how to practice.

Although they are less conventional, the lighter activities may also be considered as an extension of class activities, as more and more language teachers in France base teaching activities on the products of the media and entertainment industries. Such is the case with the English teachers at this school. Thus, students are not unaware that they can use fun materials for serious purposes. But they do not necessarily know how to use them out of the class, without a teacher's guidance. As a matter of fact, we found that students doing light activities did not all seem to consider them to be "work", and very few seemed to use them as part of a conscious learning strategy. When asked about the way they learn, the majority of the students spontaneously cite only serious activities. To find out about their lighter activities we had to ask questions such as: "Do you sometimes watch television or listen to songs in the target language?" or "Do you sometimes talk to some members of your family or friends in the target language?". It is as if for them lighter activities are simply not "learning activities". They are perceived rather as fun, games, and leisure. What seems to count for the students is to connect themselves in some way to the target language and culture and to its native speakers. Light activities are a way of simulating immersion in a distant language.

As regards the material and techniques the students use, out-of-class learning is not so unlike class learning or homework. They do more or less the same things. When compared to homework, which is an explicit extension of school into the private domain, the time management in independent learning is similar. Learning takes place at home, or on public transport and sometimes at school, during a boring class for instance. It also favours extensive learning rythm (one or two hours a week) thus copying the school model. Both homework and independent learning may involve other persons, found at school amongst friends or teachers or outside school amongst the family and friends and social networks. The only difference between homework and independent learning is that students who choose independent learning are not told what to do or not to do by a teacher. A teacher does not structure and assess their work. And grading does not come from the teacher but from oneself.

The impact on language acquisition of out-of-class learning cannot be discussed here as we have little data on the linguistic progress students made. But learning a language on one's own is not an easy task, even for motivated and skilled learners. Progress can be impeded by 
various factors that interfere with the learning process. Knowledge of the students' difficulties will help us design better conditions for efficient learning.

\subsection{The difficulties students meet}

Since it was launched, our project has involved more than fifty students and the data collected gives a rather clear overview of the factors that impact negatively on students' learning. We identified two areas of difficulties: difficulties in improving language skills and difficulties in monitoring the learning process.

Firstly, several motivated students faced difficulties in gathering the necessary resources. Learning materials may be scarce (little money at home) or unreliable (Internet problems). Some students cannot rely on out-of-school human help (experts, parents or peer support). Some encounter personal or material difficulties at home that interfere with their learning. Or, again, they may not always have a free hand with time and space there.

When asked about their difficulties in independent learning they gave all sorts of explanations related to their life conditions and organisation: "my dog was ill", "I could not find my Spanish book from last year", "I could not connect to Internet at home this week-end", "my family needs me", "I could not find someone who would work with me", "I didn't have the time" etc. It is possible that these explanations are simply face work that some students used as implicit apologies or excuses to respect the social contract (Goffman 1959). But they do inform us about differences and inequalities amongst students who, out of class, do not all live in a language-learning-friendly environment.

Secondly, some students used learning strategies that seemed to be inefficient. They set unrealistic and unreachable objectives, lacked criteria for finding and selecting resources matching their needs or their learning style. They did not know how to assess their skills and measure their progress without external help. Putting into practice out of the classroom the learning skills acquired in class is not an easy task and progress in the language is very slow. Successful learners were more skilled at learning independently and better informed about how to do it. They had more ideas about learning.

Drawing on these findings, the programme will have to be adapted so as to give students better conditions for their independent learning. Students' organisational difficulties may be partly solved by providing a SAC at the school, where students can find a quiet place for their independent learning. Moreover, the SAC will facilitate access to material and human resources such as other learners, advisors and native speakers. To help the students develop more efficient learning skills, time dedicated to advising could be extended and self-teaching techniques could be taught in class.

Finally, the reasons for learning also had an impact on the students' assiduity in learning and attending advisory sessions. Less motivated students left the programme more rapidly than others. But it appears that difficulties in joining or staying involved in the programme are also related to causes such as a lack of information about the programme combined with a lack of obligation to join it. For instance, one student had thought that she was joining an individual language course programme. When she discovered that her advisor did not speak the language she wanted to learn, she judged her advisor would be no help to her and withdrew from the programme, disappointed. The students did not all feel at ease with the idea of becoming an autonomous learner even though most of them were attracted by the idea of being in charge of their learning. One student, when realising that self-directed learning meant having to take her own decisions and being responsible for her own success, decided to end her participation in 
the programme, after two months and five advisory sessions. As the programme is not compulsory, leaving it has no negative consequences on the students' school results, whereas deciding to abandon going to class would inevitably lead to sanctions. Some parents even approved of or influenced their child's decision to stop this optional activity to concentrate more on compulsory subjects.

To prevent these difficulties, better information on the programme should be made available to students, parents and the whole school. As for the lack of obligation, it is clear that some features such as teacher supervision, external assessment, grades and sanctions may in some cases encourage the involvement in studies or, on the contrary, impede it. Some students clearly chose the programme for its optional features entailing freedom of choice and lack of sanctions, whereas others appeared unable to accept taking all the responsibilities that accompany self-directed learning (as described also by Lamb 2006). There lies another difference amongst the students who have various degrees of control on their learning.

Differences in the degree of learning autonomy and monitoring have to be taken into account in the design of the programme by providing various external motivation support schemes. For students who have difficulties in monitoring, advisors could help them discover what type of learner they are and how they could make the most of their skills. They could also help students build self-confidence and find value in their learning. The students who need more guidance could be oriented towards pre-structured activities and tutoring. Those whose motivation needs to be stimulated by an institutional recognition of their effort could be given a certificate attesting to their individual learning achievement.

\section{Conclusions}

Two main conclusions can be drawn from this research.

1. What students do to learn outside school is correlated with what they do at school and with their personal and social life. There is continuity between school and home even though these two worlds do not seem to communicate easily, in particular in class. However, during advisory sessions students can bring parts of their personal world to school (whereas in class this is more difficult) and advisors can help them to see the continuity and to establish links between school and out-of-school learning.

2. Successful out-of-class learning depends on learners fulfilling at least three necessary conditions, or success factors: motivation, learning resources and learning skills. Some students can easily find or develop these ingredients in their environment but others cannot. If one element is lacking then the learning process is likely to be interrupted. Our programme is a means for school to provide good independent learning conditions to all students who need them, through giving support to the affective (motivation), cognitive (learning skills) and material (learning resources, time and space) dimensions of learning.

In our future research we would like to establish whether or not there are connections (i) between successful out-of-class, or independent, language learning and overall results at school and (ii) between the learning strategies that students deploy and the development of their proficiency in language use.

\section{Acknowledgements}

I address my warmest thanks to my colleagues at the university, the teachers and the students at the Lycée Emmanuel Héré who participated and agreed to take part in this research. I am indebted to Harvey Moulden who helped me a lot with my academic written English. I am 
thankful to the editors for their valuable remarks on the first and last version of this paper and for their patience.

\section{References}

Bailly, S., Colaço, L., Keles, M., and Mendez, C. 2008. 'Une innovation au lycée: l'autodirection en langues', Les approches non conventionnelles en didactique des langues, Cahiers de l'Asdifle 19, 93-100.

Benson, P. and Chick, A. 'New Literacies and Autonomy in Foreign Language Learning', in M-J. Luzón, N. Ruiz, M-L. Villanueva (eds) Genres Theory and New Literacies : Applications to Autonomous Language Learning, to be published.

Bronfenbrenner, U. 1979. The Ecology of Human Development: Experiments by Nature and Design. Cambridge, MA: Harvard University Press.

Darasawang, P. and Reinders, H. 2010. 'Encouraging Autonomy with an Online Language Support System', CALL-EJ Online, 11, 2.

http://www.tell.is.ritsumei.ac.jp/callejonline/journal/11-2/darasawang reinders.html, accessed May 92010.

Giddens, A. 2003. 'The trajectory of self', in P. Du Gay, J. Evans and P. Redman (eds) Identity: a reader, London: Sage Publications, pp. 248-266.

Goffman, E. 1959. The Presentation of Self in Everyday Life, reprint London: Penguin Books 1990.

Gremmo, M-J. 1995. 'Conseiller n'est pas enseigner: le rôle du conseiller dans l'entretien de conseil', Mélanges Crapel, 22, 33-61.

Lamb, T. 2006. 'Supporting Independence : Students' perceptions of Self-Management', in T. Lamb and H. Reinders (eds) Supporting Independent Language Learning. Frankfurt am Main: Peter Lang, pp. 95-120.

Lantolf, J-P. and Genung, P-B. 2000. 'L'acquisition scolaire d'une langue étrangère vue dans la perspective de la théorie de l'activité : une étude de cas', Approches interactionnistes de l'acquisition des langues étrangères, Aile, 12. pp. 99-122.

Murray, G. 2004. 'Two Stories of Self-Directed Language Learning', in Reinders et al (eds) Proceedings of the Independent Learning Conference 2003, pp. 112-120.

Palfreyman, D. 2006. 'Social Context and Resources for Language Learning', System, 34, pp. 352-370.

Reinders, H. 2008. 'The what, why and how of language advising', MexTESOL, 32, 13-22.

\section{Website}

Langues en ligne: http://www.languesenligne.blogspot.com/

\section{Appendix - Research Interview Guideline (translated from French to English)}


Different sets of questions were submitted to students depending on the type of involvement in the program.

Type A (are still involved in the programme at the moment of the interview) Why and for what language did you take part in the programme?

Why did you choose this language?

What do you like in the programme?

What do you like less or do not like in the programme?

Do you think you will continue next year? Why?

How many times a week or a month do you study? For how long at a time?

What do you do when you study?

Is what you do in the programme useful for your English class?

Type B (joined the programme for a while then stopped it)

Why and for what language did you take part in the programme?

Why did you choose this language?

Why did you leave the programme?

Do you feel that you have learned things?

What could have helped you to continue?

Do you think you will try it again next year? Why?

Is what you did in the programme useful for your English class?

Type C (would have liked to join the programme but did not)

Why would you have liked to learn a second language?

What language and why?

Why haven't you started learning it?

What could have helped you to start studying? 